\title{
KEPADATAN POPULASI DAN KARAKTERISTIK HABITAT TARSIUS (Tarsius spectrum Pallas 1779) DI KAWASAN PATUNUANG, TAMAN NASIONAL BANTIMURUNG-BULUSARAUNG, SULAWESI SELATAN (Population Density and Habitat Characteristics of Tarsier (Tarsius spectrum Pallas 1779) at Patunuang Area, Bantimurung-Bulusaraung National Park, South Sulawesi)**
}

Maryatul Qiptiyah ${ }^{1}$ dan/and Heru Setiawan ${ }^{2}$

Balai Penelitian Kehutanan Makassar, Jl. P. Kemerdekaan Km 16,5 Makassar. Telp./Fax. (0411) 554049/554051. e-mail: ${ }^{1}$ toe21@yahoo.com. ${ }^{2}$ hiero_81@yahoo.com.

*Diterima : 14 Oktober 2010; Disetujui : 12 Desember 2012

\begin{abstract}
Tarsier is one of endemic protected animals that lives at primary or secondary forests of Sulawesi. Aim of this study was to know about population density and habitat characteristic of tarsier (Tarsius spectrum Pallas 1779) at Patunuang area, Bantimurung-Bulusaraung National Park, South Sulawesi. Population density was counted by line transect and concentration count method. Result showed that tarsius live in groups with 2-8 individuals per group, and population density at Patunuang area was 70.15 individu/ $/ \mathrm{km}^{2}$. Tarsius habitat was met on mixed forest with dense bamboo grove (Bambusa multiflex) around and karst cliff. The highest Important Value Index (IVI) of trees, poles, saplings, and seedlings in habitat respectively were: kayu nona (Metrosideros sp.,IVI=75.01), lambere (Melochia umbellate, IVI=37.08), puca (Barringtonia racemosa (L.) Spreng, IVI=19.31), and bu’rung (Ailanthus sp., IVI=25.64).
\end{abstract}

Keywords: Population density, habitat, tarsier, endemic animal

\begin{abstract}
ABSTRAK
Tarsius merupakan salah satu satwa endemik Sulawesi yang dilindungi dan hidup, baik di hutan primer maupun hutan sekunder. Penelitian ini bertujuan untuk mengkaji kepadatan populasi dan karakteristik habitat tarsius (Tarsius spectrum Pallas 1779) di Kawasan Patunuang, TN Bantimurung-Bulusaraung, Sulawesi Selatan. Penghitungan kepadatan populasi menggunakan metode transect line dan concentration count, karakteristik habitat didekati dengan analisis vegetasi menggunakan metode kuadrat. Hasil penelitian manunjukkan bahwa tarsius hidup berkelompok antara 2-8 individu dengan kepadatan populasi di kawasan Patunuang yang didapatkan selama penelitian adalah sebesar 70,15 individu $/ \mathrm{km}^{2}$. Habitat tarsius adalah hutan campuran dengan bambu (Bambusa multiflex) yang rapat sekitar celah tebing karst. Indeks Nilai Penting tertinggi pohon, tiang, pancang dan anakan masing-masing adalah kayu nona (Metrosideros sp.) (75,01), lambere (Melochia umbellata) (37,08), puca (Barringtonia racemosa (L.) Spreng) (19,31), dan bu'rung (Ailanthus sp.) (25,64).
\end{abstract}

Kata kunci: Kepadatan populasi, habitat, tarsius, satwa endemik

\section{PENDAHULUAN}

Tarsius merupakan salah satu primata terkecil dan beberapa di antara anggota spesiesnya merupakan satwa endemik Sulawesi yang terancam punah dan dilindungi. Tarsius merupakan satwa yang dilindungi berdasar Undang-Undang No. 5/ 1990 dan Peraturan Pemerintah No. 7/ 1999. Menurut IUCN (2008), tarsius dalam Red Data Book IUCN (International Union for Conservation of Nature and Natural Resources) termasuk dalam kategori vulnerable (rentan).
Tarsius mampu hidup di berbagai habitat, baik hutan primer maupun hutan sekunder. Meskipun memiliki sebaran habitat yang luas, kualitas habitat juga memegang peranan penting bagi kelestarian satwaliar pada umumnya, termasuk tarsius. Berkurangnya luasan habitat karena berbagai sebab dan atau menurunnya daya dukung habitat akan meyebabkan terjadinya penurunan populasi satwa pada umumnya, termasuk tarsius, baik secara langsung maupun tidak langsung. Sebaliknya, kualitas habitat yang baik, akan 
mendukung seluruh aktivitas tarsius, termasuk perilaku reproduksi agar dapat berjalan dengan normal.

Sumber pakan dalam habitat juga merupakan salah satu faktor ekologi yang sangat menentukan kelestarian primata. Kualitas dan kuantitas pakan dapat berpengaruh pada perilaku dan organisasi sosial primata (Raemaker dan Chivers, 1980 dalam Bismark, 1994). Selain itu, pakan juga mempengaruhi luas daerah jelajah berhubungan dengan perilaku pergerakan primata di samping upaya pemenuhan sumber energi untuk pertumbuhan dan berkembang biak (Bismark, 1994).

Taman Nasional (TN) BantimurungBulusaraung merupakan salah satu kawasan yang menjadi habitat tarsius di Sulawesi. TN Bantimurung-Bulusaraung ditetapkan berdasar Surat Keputusan Menteri Kehutanan Nomor 398/Menhut-II/ 2004. Penelitian tarsius pada umumnya banyak dilakukan di Sulawesi bagian utara dan tengah. Sementara itu, menurut Gursky et al. (2009) di Sulawesi Selatan status populasi dan tingkat kelangkaan Tarsius spectrum Pallas 1779 belum bisa ditetapkan secara pasti karena kurang data. Hal ini berarti bahwa penelitian tarsius di Sulawesi bagian selatan masih perlu dilakukan.

Penelitian ini bertujuan untuk mendapatkan data dan informasi tentang populasi, karakteristik habitat, dan potensi pakan tarsius di kawasan hutan Patunuang, TN. Bantimurung-Bulusaraung. Adapun manfaat penelitian ini adalah dapat digunakan sebagai acuan dalam upaya pengelolaan taman nasional, populasi dan habitat tarsius khususnya.

\section{BAHAN DAN METODE}

\section{A. Waktu dan Lokasi Penelitian}

Penelitian dilaksanakan pada bulan April-Oktober 2009 di kawasan hutan Patunuang, TN Bantimurung-Bulusaraung, Sulawesi Selatan. TN. Bantimurung-Bulusaraung memiliki luas \pm 43.750 ha, ter- letak di wilayah administratif Kabupaten Maros dan Kabupaten Pangkep, Provinsi Sulawesi Selatan. Secara geografis kawasan hutan ini terletak antara

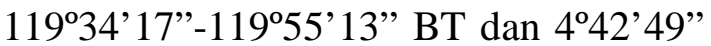
$-5^{\circ} 06^{\prime} 42^{\prime \prime}$ LS.

Iklim di kawasan TN BantimurungBulusaraung bervariasi di masing-masing kelompok lokasi yaitu berkisar dari tipe B sampai dengan D. Sementara itu curah hujan juga bervariasi antar lokasi, yaitu berkisar antara 2.250-3.750 mm. Formasi batuan yang ada di TN Bantimurung-Bulusaraung terbagi menjadi tujuh kelompok yang tersebar di berbagai lokasi (Taman Nasional Bantimurung-Bulusaraung, 2008).

Patunuang merupakan kawasan hutan dengan potensi keanekaragaman hayati yang paling tinggi. Secara umum bentangan alam lokasi pengamatan berupa aliran sungai yang diapit oleh tebing-tebing curam dengan kelerengan $\geq 80^{\circ}$. Tebing yang berada di kanan-kiri sungai mempunyai ketinggian 25-30 meter. Formasi bebatuan di pinggir sungai tersusun oleh batu kapur (Anonim, 2007).

Apabila diamati lebih teliti, bongkahan-bongkahan batu di kanan-kiri sungai membentuk lubang-lubang gua. Daerah sempadan sungai ditumbuhi oleh beberapa jenis vegetasi mulai dari tumbuhan tingkat semai, pancang, tiang, dan pohon. Selain sempadan sungai, kawasan Patunuang juga memiliki hamparan yang banyak terdapat rumpun bambu yang juga merupakan habitat bagi tarsius. Berkaitan dengan hal tersebut, penelitian dilakukan di 10 titik lokasi sekitar tempat tidur atau yang menjadi sarang tarsius. Secara lengkap lokasi pengamatan selama penelitian tersaji pada Tabel 1.

\section{B. Bahan dan Alat Penelitian}

Bahan penelitian yang digunakan adalah bagian vegetasi habitat dan lokasi bersarang tarsius dan sebagai alat pembantu penelitian diperlukan peta dasar, peta kerja, GPS, meteran, tali plastik, parang, 
Tabel (Table) 1. Posisi lokasi pengamatan habitat tarsius di kawasan hutan Patunuang, TN BantimurungBulusaraung, Sulawesi Selatan tahun 2009 (Survey locations of tarsier habitat at Patunuang area, Bantimurung-Bulusaraung National Park, 2009)

\begin{tabular}{|c|c|c|c|c|}
\hline No. & Garis lintang (Latitude) (LU) & Garis bujur (Meridian) (BT) & Ketinggian (Altitude) (m) & Lokasi (Location) \\
\hline 1. & 503’10,8” & $119^{\circ} 43^{\prime} 06,4^{\prime \prime}$ & 89 & Pos I \\
\hline 2. & 503’15,8” & $119^{\circ} 43 ’ 06,3 ”$ & 104 & Pos II \\
\hline 3. & $5^{\circ} 03^{\prime} 25,3^{\prime \prime}$ & $119^{\circ} 42^{\prime} 25,2^{\prime \prime}$ & 100 & Beslap I \\
\hline 4. & $5^{\circ} 03$ '42,9”' & $119^{\circ} 42^{\prime} 29,5^{\prime}$ & 100 & Beslap II \\
\hline 5. & $5^{\circ} 03^{\prime} 55,6^{\prime \prime}$ & $119^{\circ} 42^{\prime} 58,6^{\prime \prime}$ & 250 & Pampang I \\
\hline 6. & 503’57,2” & $119^{\circ} 43^{\prime} 00,6^{\prime}$ & 200 & Pampang II \\
\hline 7. & $5^{\circ} 04^{\prime} 45,1^{\prime \prime}$ & $119^{\circ} 42^{\prime} 25,2^{\prime}$ & 575 & Parang Tembo I \\
\hline 8. & $5^{\circ} 04^{\prime} 47,7^{\prime \prime}$ & $119^{\circ} 42^{\prime} 29,5^{\prime \prime}$ & 562 & Parang Tembo II \\
\hline 9. & $5^{\circ} 04^{\prime} 54,0^{\prime \prime}$ & 11943’15,7” & 458 & Pute’ I \\
\hline 10. & $5^{\circ} 05^{\prime} 00,4^{\prime \prime}$ & $119^{\circ} 43^{\prime} 25,5^{\prime \prime}$ & 388 & Pute’'II \\
\hline
\end{tabular}

cethok, kamera, binokular, sarung tangan, termometer tanah, termometer udara, alat pengukur intensitas cahaya (light meter), altimeter, kemiringan, higrometer, kuas, tally sheet, serta alat tulis.

\section{Metode Penelitian}

\section{Cara Kerja}

\section{a. Populasi Tarsius}

Pendataan populasi tarsius dilakukan dengan cara sampling menggunakan perpaduan antara metode line transect dan concentration count. Wilayah yang diteliti dibagi menjadi dua strata yaitu hutan sekunder dan kawasan hutan yang dekat dengan pemukiman. Metode line transect digunakan untuk hutan sekunder dengan menggunakan jalan setapak sebagai transek utamanya. Sementara concentration count digunakan untuk kawasan yang sudah diketahui sebagai habitat tidur tarsius. Pohon tidur tarsius digunakan sebagai fokus area pada metode ini.

Data yang dicatat adalah jumlah individu atau kelompok tarsius berdasarkan pengamatan langsung atau tidak langsung (suara). Sementara jumlah individu pada satu kelompok ditentukan dengan asumsi bahwa dalam satu kelompak paling sedikit dijumpai dua individu tarsius (Marker, 2006).

Pada metode line transect dengan panjang total transek $3 \mathrm{~km}$, dugaan populasi tarsius dihitung berdasarkan perjumpaan langsung maupun tidak langsung (suara) dan dicatat jarak antara posisi sat- wa dengan posisi pengamat. Sementara pada metode concentration count dengan luasan area pengamatan 44,74 ha diamati perjumpaan langsung maupun tidak langsung (suara) pada lokasi yang didominasi pohon bambu sebagai pohon tidur kelompok tarsius.

\section{b. Populasi dan Keragaman Vegetasi sebagai Habitat Tarsius}

Analisis karakteristik habitat tarsius, dilakukan dengan metode kuadrat (Mueller-Dumbois dan Ellenberg, 1974 dan Kusmana, 1997). Pohon dianalisis dalam petak kuadrat ukuran 20 m x 20 m, tiang dalam petak kuadrat ukuran $10 \mathrm{~m}$ x $10 \mathrm{~m}$, dan pancang dalam kuadrat petak ukuran $5 \mathrm{~m}$ x $5 \mathrm{~m}$; sedangkan anakan pada petak kuadrat ukuran $2 \mathrm{~m}$ x $2 \mathrm{~m}$. Setiap ukuran petak diletakkan di sekitar habitat tarsius terutama habitat tidurnya.

\section{c. Parameter Fisik Lingkungan Habitat}

Parameter fisik lingkungan habitat meliputi ketinggian, topografi, temperatur udara, kelembaban udara, dan intensitas cahaya yang diukur di setiap habitat tarsius, terutama habitat tidurnya. Pada masing-masing habitat tarsius dilakukan pengukuran parameter fisik lingkungan sebanyak tiga kali.

\section{Analisis Data}

\section{a. Populasi Tarsius}

Pendugaan populasi dengan metode line transect, dihitung dengan menggunakan persamaan: 
$\mathbf{D}=\frac{n}{2 L}\left(\frac{1}{n} \sum \frac{1}{z i}\right)$

dengan:

$\mathrm{D}$ = estimasi kepadatan

$\mathrm{n}=$ jumlah individu yang tercatat

$\mathrm{L}=$ panjang transek

zi $=$ jarak pandang tiap individu

Pendugaan populasi untuk metode concentration count dilakukan dengan penghitungan langsung pada saat ditemukan primata tersebut. Jumlah individu terbesar yang ditemui dari seluruh rangkaian pengamatan diasumsikan sebagi jumlah individu yang mewakili satu kelompok. Apabila jumlah inidividu terkecil yang ditemui diasumsikan bahwa individu yang lain tidak terlihat pada saat pengamatan (Fachrul, 2007).

1) Populasi Tiap Kelompok: $\mathrm{Pj}=\left(\sum \mathrm{Xi}\right) /$ $\mathrm{n}$, dengan $\mathrm{Pj}=$ populasi pada lokasi pengamatan ke-j (individu), $\mathrm{Xi}=$ jumlah individu yang dijumpai pada pengamatan ke-i (individu), $\mathrm{n}=$ jumlah ulangan pengamatan.

2) Rata-rata Populasi: pj $=\left(\sum \mathrm{Pj}\right) / \mathrm{j}$, dengan pj = rata-rata populasi pada lokasi pengamatan ke-j (individu), $\mathrm{Pj}=$ populasi pada lokasi pengamatan ke-j (individu), $\mathrm{j}=$ jumlah blok pengamatan.

3) Kerapatan Populasi: $\mathrm{D}=\mathrm{pj} / \mathrm{Aj}$, dengan $\mathrm{D}=$ kerapatan (densitas) populasi (individu/hektar), $\mathrm{pj}$ = rata-rata populasi pada lokasi pengamatan ke-j (indivi$\mathrm{du}), \mathrm{Aj}=$ luas area lokasi pengamatan ke-j (hektar).

\section{b. Populasi dan Keragaman Vegetasi sebagai Habitat Tarsius}

Analisis data vegetasi dilakukan untuk mendapatkan nilai-nilai Kerapatan (K), Kerapatan Relatif (KR), Frekuensi (F), Frekuensi Relatif (FR), Dominansi (D), Dominansi Relatif (DR), dan Indeks Nilai Penting (INP).

Indeks Nilai Penting (INP) adalah : $\mathrm{INP}=\mathrm{KR}+\mathrm{FR}+\mathrm{DR}$

\section{HASIL DAN PEMBAHASAN}

\section{A. Kepadatan Populasi Tarsius}

Analisis kepadatan populasi T. spectrum selama penelitian menggunakan pendekatan metode yang berbeda di dua kelompok lokasi habitat. Di lokasi sepanjang aliran sungai Patunuang, penghitungan populasi menggunakan metode transek dan di lokasi Parang Tembo dan Pute' didekati dengan metode concentration count.

Selama penelitian, tarsius dijumpai di berbagai lokasi penelitian, baik di sepanjang sungai Patunuang maupun di lokasi Parang Tembo dan Pute'. Perjumpaan tarsius di lokasi sepanjang sungai Patunuang hanya secara tidak langsung atau dengan kata lain hanya terdeteksi dari suara. Hal ini karena tarsius bersarang di tebing-tebing karst yang bervariasi ketinggiannya, yaitu antara 10-20 meter dari permukaan tanah (Gambar 1). Selama penelitian, sedikitnya dijumpai enam kelompok tarsius berdasarkan suara yang berasal dari tebing karst di samping sungai Patunuang.

Tarsius keluar dari sarang sekitar jam 18.00 WITA saat akan mencari makan. Pada saat ini tarsius mengeluarkan suara sebagai penanda teritori, dan hal yang sama terjadi ketika tarsius akan kembali ke sarang. Selama penelitian, suara tarsius lebih mudah dideteksi pada saat pagi hari sekitar jam 05.00-06.30 WITA, dibandingkan pada saat sore hari.

Sementara itu di lokasi Parang Tembo dan Pute, tarsius dijumpai bersarang di rumpun bambu duri (Bambusa multiflex Raeusch.) yang sangat rapat. Rumpun bambu yang digunakan sebagai sarang tarsius memiliki batang tua paling sedikit delapan batang per rumpun (Gambar 2). Rumpun bambu digunakan sebagai tempat tidur dan tempat berlindung (cover) di mana tarsius membangun sarang di bagian bawah rumpun bambu yang cukup rapat dan dari kemungkinan serangan predator, seperti ular dan burung hantu 


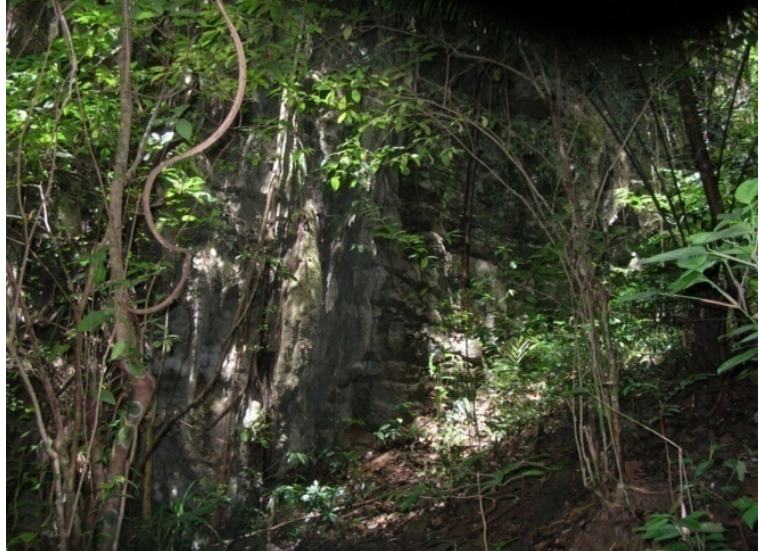

Gambar (Figure) 1. Karakteristik lokasi sarang tarsius yang dijumpai di Tebing Karst di sisi Sungai Patunuang (Characteristic of tarsier nest location on karst cliff along Patunuang river banks)

(Anonim, 2007). Penelitian yang dilakukan oleh Himakova (Anonim, 2007), menyatakan bahwa selama penelitian, minimal dijumpai 2-4 kelompok tarsius di lokasi Parang Tembo dan Pute', dengan jumlah individu masing-masing kelompok berkisar antara 2-8 individu.

Hasil penelitian menunjukkan bahwa kepadatan tarsius di lokasi sekitar sungai Patunuang pada saat musim penghujan sebesar 0,525 individu/ha atau $52,5 / \mathrm{km}^{2}$. Sementara itu, kepadatan tarsius yang dihitung pada saat musim kemarau sedikit berbeda dibanding musim hujan, yaitu sebesar 0,656 individu/ha atau 65,6 indivi$\mathrm{du} / \mathrm{km}^{2}$. Hal ini sesuai keterangan Pado (Komunikasi Pribadi), bahwa vokalisasi tarsius akan lebih mudah didengar pada musim kemarau daripada musim Penghujan. Dengan demikian rata-rata kepadatan populasi tarsius di sekitar sungai Patunuang sebesar 0,5905 individu/ha atau sebesar 59,05 individu $/ \mathrm{km}^{2}$.

Populasi tarsius di lokasi habitat Parang Tembo memiliki kepadatan populasi sebesar $0,083 /$ ha atau 8,3 individu/ $\mathrm{km}^{2}$, dengan menggunakan metode concentration count. Sementara itu di lokasi Pute kepadatan populasi 0,028 individu/ha atau 2,8 individu $/ \mathrm{km}^{2}$. Dengan demikian, estimasi kepadatan populasi tarsius maksimal di kawasan Patunuang selama penelitian adalah sebesar 0,7015 indivi$\mathrm{du} / \mathrm{ha}$ atau 70,15 individu/ $\mathrm{km}^{2}$.

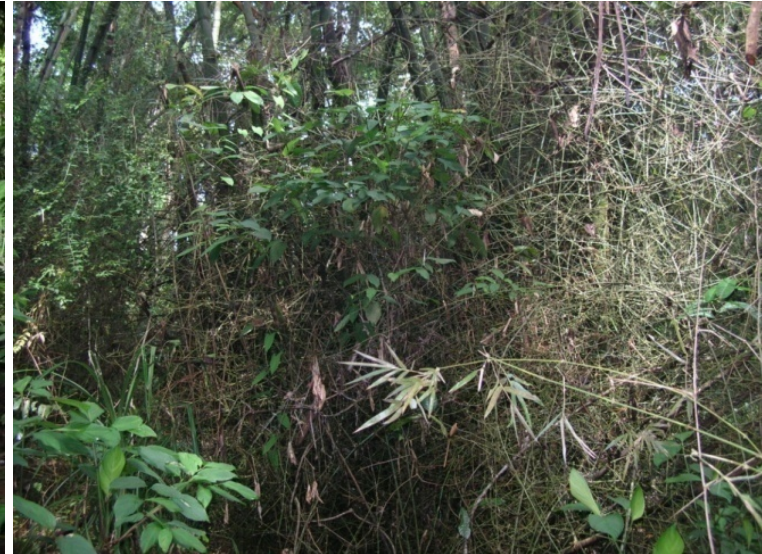

Gambar (Figure) 2. Rumpun bambu yang menjadi habitat tidur tarsius (Bamboo clumps as tarsier resting site)

Selama penelitian, tarsius lebih mudah terdeteksi, baik secara langsung maupun vokalisasinya di musim kemarau daripada musim penghujan. Menurut Gursky (2000), bahwa hal ini berkaitan dengan adanya fluktuasi sumberdaya pakan. Pada musim hujan, sumberdaya pakan lebih melimpah dibandingkan pada musim kemarau sehingga tarsius hanya sedikit menggunakan waktu untuk mencari makan. Sebaliknya, di musim kemarau tarsius lebih mudah terdeteksi karena sumberdaya pakan lebih sedikit, sehingga membutuhkan lebih banyak waktu dan pergerakan untuk mencari makan di bandingkan musim hujan. Lokalisasi dapat mengidentifikasikan teritorial sumber pakannya.

\section{B. Karakteristik Habitat}

Berdasar hasil penelitian, tarsius di kawasan Patunuang bersarang di beberapa tempat dengan karakteristik habitat seperti kawasan sekitar aliran sungai Patunuang dan di celah tebing karst. Sementara itu di lokasi Parang Tembo dan Pute, tarsius ditemukan bersarang di rumpun bambu duri yang rapat, yaitu memiliki jumlah batang tua minimal delapan batang dalam satu rumpun. Tarsius memilih sarang pada rumpun bambu yang rapat sebagai upaya menghindar dari predator. 
Secara umum peranan vegetasi bagi kehidupan satwaliar termasuk tarsius adalah sebagai tempat untuk berlindung, tidur, dan bersarang. Berdasarkan hasil penelitian, tarsius dijumpai bersarang di celah tebing karst dan di dalam rumpun bambu yang rapat. Namun demikian, jenis vegetasi lain yang ada di sekitar sarang juga berperan penting, yaitu untuk membantu pergerakan tarsius dalam aktivitas hariannya, seperti mencari makan.

Beberapa jenis tumbuhan di sekitar habitat tidur tarsius yang memiliki INP tertinggi dari tingkat pohon, tiang, pancang, dan semai masing-masing adalah jenis kayu nona (Metrosideros sp.) sebesar 75,01; lambere (Melochia umbellata) sebesar 37,08; bu'rung (Ailanthus sp.) sebesar 25,64; paliasa (Kleinhovia hospita) sebesar 24,34. Hal ini berarti secara ekologi komposisi jenis-jenis tersebut menunjukkan sebagai karakteristik habitat.

Tumbuhan memiliki arti penting bagi aktivitas harian tarsius. Selama pergerakannya, tarsius membutuhkan cabang pohon dengan diameter kecil $(<4 \mathrm{~cm})$ terutama untuk berburu dan menjelajah. Diameter sedang $(4-8 \mathrm{~cm})$ terutama digunakan untuk istirahat dan menandai daerah jelajah (home range), sedangkan diameter $>8 \mathrm{~cm}$ juga digunakan untuk istirahat dan menandai daerah jelajah (home range) meskipun tidak sebanyak diameter sedang (MacKinnon dan MacKinnon, 1980). Selain sebagai sarana dalam mobilisasi, kehadiran berbagai jenis tumbuhan juga berperan dalam menciptakan mikroklimat untuk kehidupan serangga dan serangga merupakan sumber pakan utama tarsius.

Wirdateti dan Dahrudin (2008), selama penelitian juga dijumpai beberapa jenis tumbuhan yang digunakan intensif dalam aktivitas tarsius adalah paliasa ( $K$. hospita), Ficus spp., mali-mali (Leea indica (Burm f.) Merr.), dan jambu biji (Syzygium aqueum (Burm.f.) Alston 1929).

Lokasi sarang tarsius di kawasan Patunuang memiliki kelerengan yang bervariasi, yaitu dari yang landai dengan kele- rengan sekitar $4 \%$ sampai dengan kelerengan terjal, sekitar $80 \%$, sementara itu ketinggian lokasi sarang tarsius berkisar antara 89-575 $\mathrm{m}$ di atas permukaan laut (dpl). Hal ini sesuai dengan Wirdateti dan Dahrudin (2006) yang menyatakan bahwa tarsius mampu hidup di habitat yang bervariasi, dari dataran rendah hingga ketinggian $1.300 \mathrm{~m}$ dpl.

Hasil penelitian menunjukkan bahwa suhu udara di kawasan Patunuang berkisar antara $27,63-35,87^{\circ} \mathrm{C}$ pada musim penghujan dan berkisar antara 28,73$35,37^{\circ} \mathrm{C}$ pada musim kemarau. Kelembaban udara di sekitar habitat tarsius berkisar antara 64,03-83,6\% pada musim penghujan dan berkisar antara 43,4372,23\%. Tekanan udara berkisar antara 975,10-1.035,33 HPa di musim Penghujan dan berkisar antara 969,57-1.036,40 Hpa pada musim kemarau. Intensitas cahaya berkisar antara 246,67-2363,33 lux di musim penghujan dan berkisar antara 410-6286,67 lux pada musim kemarau. Kelembaban tanah berkisar antara 41,6790\% di musim penghujan dan berkisar antara $25-90 \%$ pada musim kemarau, $\mathrm{pH}$ tanah berkisar antara 3,73-5,93 di musim penghujan dan berkisar antara 3,70-6,67 pada musim kemarau. Curah hujan ratarata per bulan selama penelitian berkisar $0 \mathrm{ml}$ (tidak ada hujan), terjadi pada bulan Agustus dan September sampai dengan $15 \mathrm{ml}$, terjadi pada bulan Mei.

Faktor fisik lingkungan tersebut berpengaruh secara tidak langsung terhadap ciri kehidupan tarsius. Fluktuasi faktor fisik lingkungan akan mempengaruhi pola fenologi vegetasi (White, 1998). Bagi tarsius, perubahan pola fenologi akan mempengaruhi komposisi dan kelimpahan serangga sebagai sumber pakannya.

\section{Implikasi Pengelolaan}

Tarsius yang dijumpai di TN Bantimurung-Bulusaraung adalah T. spectrum khas Sulawesi Selatan (Shekelle, 2008). Kepadatan populasi $T$. spectrum di kawasan hutan Patunuang, TN Bantimurung-Bulusaraung, Sulawesi Selatan jauh 
lebih sedikit dibandingkan $T$. spectrum di Tangkoko Batuangus, Sulawesi Utara. Menurut Gursky (1998) kepadatan populasi T. spectrum di Tangkoko Batuangus di habitat hutan primer memiliki kepadatan populasi 156 individu/ $\mathrm{km}^{2}$. Rendahnya populasi tarsius di kawasan Patunuang, TN Bantimurung-Bulusaraung pada saat penelitian diduga karena populasinya belum pulih akibat adanya perburuan pada beberapa tahun yang lalu (Pado, Komunikasi Pribadi, 2009).

Hasil penelitian menunjukkan bahwa lokasi yang menjadi habitat utama tarsius di kawasan Patunuang, TN BantimurungBulusaraung adalah di dalam rumpun bambu yang rapat dan celah tebing karst. Lokasi yang ditemui adanya tarsius adalah di Parang Tembo dan Pute untuk kawasan yang memiliki rumpun bambu sebagai habitat tidur tarsius. Rumpun bambu yang digunakan sebagai tempat tidur adalah rumpun bambu yang rapat sehingga menghindarkan tarsius dari serangan predator.

Di sisi lain, bambu memiliki banyak manfaat bagi kehidupan masyarakat sehari-hari. Hal ini berpotensi memanfatkan bambu sehingga mengurangi vegetasi habitat tidur tarsius. Lebih jauh, hal tersebut mengancam kelestarian tarsius di masa yang akan datang. Pembatasan dalam pemanfaatan bambu di habitat tarsius perlu diformulasikan sehingga kebutuhan masyarakat terpenuhi dan habitat tarsius tetap terjaga.

Sementara celah tebing karst yang digunakan sebagai habitat tidur tarsius adalah di sepanjang sungai Patunuang, terutama di dekat "Biseang Labboro". Hal ini berarti bahwa dalam upaya perlindungan dan pelestarian tarsius, lokasi tersebut merupakan lokasi penting untuk dilindungi, baik dari upaya perburuan atau pun kualitas habitat secara keseluruhan.

Pentingnya perlindungan vegetasi di sekitar tebing karst, terutama di dekat "Biseang Labboro" perlu dilakukan karena tempat ini merupakan tempat wisata yang banyak diminati masyarakat. Ke- giatan berkemah yang biasa dilakukan oleh sebagian wisatawan perlu diatur sedemikian rupa (misal, diingatkan untuk tidak membuat gaduh), sehingga tidak mengganggu aktivitas tarsius.

Vegetasi merupakan salah satu komponen habitat yang memiliki arti penting bagi peri kehidupan harian tarsius. Batang dan percabangan vegetasi digunakan tarsius sebagai sarana untuk melakukan pergerakan harian, termasuk dalam mencari makan. Di samping itu, vegetasi yang beranekaragam turut menciptakan iklim mikro bagi kehidupan organisme lain termasuk serangga yang berpotensi sebagai pakan tarsius.

Kelimpahan dan keragaman vegetasi perlu dipertahankan untuk menunjang kehidupan tarsius. Selama penelitian, tidak dijumpai laporan adanya penebangan pohon untuk berbagai keperluan oleh masyarakat dan kondisi ini perlu dipertahankan.

Secara umum, kawasan Patunuang merupakan hutan sekunder yang diselingi dengan areal sawah tadah hujan dan pemukiman. Seiring dengan bertambahnya penduduk yang mendiami kawasan tersebut, tidak menutup kemungkinan akan menjadi salah satu ancaman terhadap kelestarian tarsius apabila tidak diikuti upaya perlindungannya. Pertambahan penduduk akan mengakibatkan perubahan tataguna lahan di luar kawasan hutan untuk pemukiman atau ladang yang berarti mengurangi luasan habitat tarsius. Kekhawatiran terhadap ancaman kelestarian tarsius sejalan dengan pernyataan Gursky (1998), yaitu tarsius lebih melimpah di hutan sekunder daripada di hutan primer. Meskipun demikian, tarsius lebih besar jumlahnya pada kawasan yang dilindungi dibandingkan dengan kawasan yang tidak dilindungi.

\section{KESIMPULAN DAN SARAN}

\section{A. Kesimpulan}

1. Kepadatan maksimal populasi tarsius di kawasan Patunuang yang didapat- 
kan selama penelitian adalah sebanyak 0,7015 individu/ha atau 70,15 individu $/ \mathrm{km}^{2}$.

2. Karakteristik habitat tidur tarsius yang teramati selama penelitian adalah di lubang tebing karst sekitar aliran sungai Patunuang dan di dalam rumpun bambu duri (Bambusa multiflex Raeusch.). Vegetasi yang memiliki dominansi tinggi dan berperan penting pada aktivitas tarsius yang dijumpai dalam penelitian adalah paliasa (Kleinhovia hospita Linn.), Ficus spp., mali-mali (Leea indica (Burm f.) Merr.), dan jambu biji (Syzygium aqueum (Burm.f.) Alston, 1929).

\section{B. Saran}

1. Dinamika populasi Tarsius spectrum Pallas, 1779 di kawasan hutan Patunuang TN Bantimurung-Bulusaraung masih perlu diamati secara rutin dan dianalisis lebih lanjut untuk dapat menentukan status konservasi $T$. spectrum khas Sulawesi Selatan.

2. Habitat tarsius di kawasan hutan Patunuang yang penting untuk dilindungi adalah lubang-lubang pada tebing karst, rumpun bamboo, dan vegetasi pendukung lainnya.

\section{UCAPAN TERIMAKASIH}

Terimakasih penulis ucapkan kepada semua pihak yang telah memfasilitasi dan terlibat dalam penelitian, yaitu Kepala Balai Penelitian Kehutanan Makassar, Kepala Balai dan staff Balai Taman Nasional Bantimurung-Bulusaraung, $\mathrm{M}$. Azis Rakhman, Mursidin, Fajri, Syaiful Fajrin, dan Pado.

\section{DAFTAR PUSTAKA}

Institut Pertanian Bogor. (2007). Surili: Eksplorasi Budaya, Flora dan Fauna Ekosistem Karst Maros-Pangkep bagi Pengembangan Ekowisata di Taman nasional Bantimurung-Bulusa- raung Provinsi Sulawesi Selatan. (Laporan ilmiah akhir). Kerjasama Himakova Fakultas Kehutanan IPB, Departemen Kehutanan dan WWF, Bogor.

Bismark, M. (1994). Ekologi makan dan perilaku bekantan (Nasalis larvatus Wurmb.) di hutan bakau Taman Nasional Kutai, Kalimantan Timur. (Disertasi Program Pasca Sarjana). Institut Pertanian Bogor, Bogor.

Facrul, M., F. (2007). Metode sampling bioekologi. Jakarta: Bumi Kasara.

Gursky, S. (1998). The conservation status of two sulawesian tarsier species. Primates Conservation, 18, 88-91.

Gursky, S. (2000). Effect of seasonality on the behavior of an insectivorous primate, tarsius spectrum. International Journal of Primatology, 21(3). Diunduh 25 November 2009 dari www.springerlink.com.

Gursky, S., Shekelle, M., \& Nietsch, A. (2009), The conservation status of Indoneisa's tarsier. Dalam Primates the Oriental Night. Diunduh 30 September 2009 dari www.tarsier.org.

IUCN, (2008). The IUCN red list of threatened species. Diunduh 10 Desember 2008 dari www.iucnredlist .org.

Kusmana,C. (1997). Metode Survei Vegetasi, Bogor: IPB Press.

MacKinnon, J., \& MacKinnon, K. (1980), The behavior of wild pectral tarsiers. International Journal of Primatology, 1(4). Diunduh 25 November 2009 dari www.springerlink.com.

Marker, S. (2006). Habitat-specific ranging pattern of dian's tarsier (Tarsius dianae) as revealed by radiotracking. Diunduh 12 November 2008 dari www.interscience.wiley.com.

Mueller-Dumbois, D., \& Ellenberg, H. (1974). Aims and methods of vegetation ecology. Toronto: John Wiley \& sons.

Shekelle. M. (2008). Distribution and biogeography of tarsier. Dalam Primates the Oriental Night. Diunduh 
30 September 2009 dari www.tarsier .org

Taman Nasional Bantimurung-Bulusaraung. (2008). Rencana Pengelolaan Jangka Panjang Taman Nasional Bantimururng-Bulusaraung Periode 2008-2027, Kabupaten Maros dan Pangkep Provinsi Sulawesi Selatan. Diunduh 12 Desember 2008 dari www.dephut.go.id.

White, F.J. (1998). The importance of seasonality in primatology. Interna- tional Journal of Primatology, 19 (6). Diunduh 25 November 2009 dari www.springerlink.com.

Wirdateti, \& Dahrudin, H. (2008). Pengamatan habitat, pakan dan distribusi Tarsius tarsier (Tarsius) di Pulau Selayar dan TWA Patunuang, Sulawesi Selatan. Biodiversitas, 9 (2), 152155. Diunduh 1 September 2009 dari www.unsjournal.com. 